\title{
Kids and Thermostats: Understanding Children's Involvement with Household Energy Systems
}

\author{
Michael S. Horn, Zeina Atrash Leong, Michael D. Greenberg, Reed Stevens \\ Computer Science and Learning Sciences \\ Northwestern University \\ 2120 Campus Drive \\ Evanston, Illinois 60208 USA \\ michael-horn@northwestern.edu
}

\begin{abstract}
We present a study of family practices around the use of thermostats to control residential heating and cooling systems. Our analysis is focused on the role of children and adolescents and factors that affect their participation in the management of household energy consumption. As "smart" technologies become more common in homes, our goal is to understand how we might involve parents and children together in learning about issues of environmental sustainability. Based on interviews with families, thermostat installers, and a thermostat designer, our findings suggest that thermostats tend to be adult-only devices. Children rarely (and sometimes never) adjust the temperature or program settings, and there appears to be limited opportunity for youth to become more involved as they get older. We encountered variation in family practices along dimensions such as age, economic situation, environmental attitudes, and type of heating and cooling equipment. Despite this variation, however, there was a pervasive lack of interest and awarenesson the part of children, even among those who reported adjusting thermostats on occasion. Based on these findings, we discuss how this situation might be changed through the design of new technologies to raise awareness while creating more active and distributed participation.
\end{abstract}

Keywords:Thermostats, children, families, homes, design, environmental sustainability.

\section{Introduction}

The technologiesthat families use to control householdheating and cooling systems areincreasingly "smart", interconnected, and distributed. These changes are helping move user interfacesoff of walls and onto the screens of smartphones and tablet computers. With these changes come new opportunities to help families do a better job managing energy consumption while saving money and staying comfortable at the same time. There are also newways to help families reflect on issues of environmental sustainability and the role of individual consumption in relation to global climate change. Despite these opportunities, the promise of new technology often remains unfulfilled, in part because designers fail to fully understand the complexities of existing socio-technical systems. Habits, social norms, and interactions among family members can all shape behavior in unexpected ways $[2,6,34]$. The presence of "smart" technology alone 
does not necessarily translate to increased knowledge or motivation to reduce wasteful consumption.

In this work we are interested in the role of children and adolescents in helping families think about energy consumption. In particular, as technology changes, what opportunities will there be to help children learn about how energy is usedin homes? Going further, how might we involve youth as active co-participants with parents and other family members in leading more sustainable lifestyles? In trying to answer these questions, we argue that it is important not only to look to the future, but also to look to the present (or near past) to understand family practices around existing energy infrastructuresas a way to inspire designers while avoiding pitfalls of the status quo.

To this end,we present a qualitative study of family practices around the use of residential thermostats in the United States Midwest. One of our key findings is that children and adolescents rarely (and sometimes never) adjust the temperature or program settings. This finding might seem obvious given that the management of heating and cooling systems isoften thought of as a dangerous and costly activity. However, in this paper our aim is to develop a deeper understanding of why this is the case. As Shove has argued, mundane and routine aspects of everyday life merit scrutiny precisely because social constructions of normality have contributed to a ratcheting up of demand for energy-intensive services and lifestyles[40]. In other words, energy-intensive products and services that were once considered luxuries are now seen as necessities of everyday life. With these changes come corresponding shifts in the roles that various participants in family life are expected to play. A reason to study "normal" practices is that expectations about who can and should participate can change over time and that interaction design is one powerful way to bring about such change. This does not necessarily mean that kids should be responsible for controlling central heating and air conditioning systems - althoughthis isn't out of the question — but mobile and connected technologies offer new ways for kids to be involved in helping learn about energy consumption while influencing family decisions across a range of household infrastructures (beyond just central heating and air conditioning).

In this work we adopt a view of learning as a transformation of participation in a community over time [30, 38, 39]. For our purposes this means that children learn, in part, by becoming more active collaborators with adults in consequential activity. With these changes come corresponding shifts in identity - how children view themselves and their role in the familyover time. With respect to household energy management (and the use of thermostats, in particular) this perspective orients our analysis to pay attention to how the role of children and adolescents might evolve as they get older.

Studying family practices around thermostats is not a trivial concern; heating and cooling accounts for roughly $30 \%$ of domestic energy use in the United States and other developed 
countries[8]. More than that, however, as we imagine a future of ubiquitous household technology, are we making implicit assumptions about our target audience? And, if so, are we needlessly, and perhaps detrimentally, excluding the participation of children and youth?

\section{Background}

\subsection{Technology and Sustainability}

We consider thermostats to be an instance of a broader class of technologies used to manage consumption of household resources such as natural gas, water, electricity, and heating oil [21]. Some of this technology (often described with the term eco-feedback [13]) is explicitly designed to promote environmental sustainability by raising awareness of consumption in terms of its magnitude and impact. While research in environmental psychology has studied eco-feedback in various forms for the better part of thirty years [13], more recent work in human-computer interaction has focused on the development of inexpensive sensing technology [12, 27, 32], innovative interaction designs $[1,7,11,13,16]$, and an exploration of economic and psychological models of behavior change (e.g. $[11,13,17,36])$. The motivation for this research stems in part from therecognition that modern domestic infrastructureshave made the generation, transport, and consumption of natural resources largely invisible [3]. Even though resources are precisely monitored and billed, households are largely unaware of the magnitude of their own consumption $[3,6,25,34,36]$.

Along with advances in eco-feedback design, there is also a growing interest in understanding the interplay between technology and everyday social activities in homes $[5,18,26,34,35,42$, $43,45,46]$. This shift in emphasis brings about a corresponding shift in the unit of analysis from the behavior of individuals to the sociocultural practices of communities as mediated by technology $[26,35,40]$. Technology design from this perspective is understood as more than providing information to consumers so as to close feedback loops. Because artifacts play an integral role in shaping human activity [26, 28, 29, 40], design can be understood as a way to help reconfigure existing practices - a strategy referred to as "practice as a unit of intervention" [35] or as a "practice as a unit of design" [26]. This emphasis on sociocultural practices is useful in part because everyday practices are entangled with cultural value systems and norms that help set expectations about who can and should engage in an activity and what form that participation take $[30,38,39]$. These issues become especially relevant when certain groups, who might otherwise be meaningful contributors, are largely excluded from an activity. In the case of children and adolescents this is particularly concerning because youth are not only consumers of natural resources in their own right, but are the next generation of adults who will face increasingly critical and complex challenges related to energy, water, climate change, and the environment.In this we agree with Ballantyne, Connell, and Fien [2]who argue that children are not simply recipients of environmental knowledge transferred from adults, but are active influencers of adult behavior and thought. 



Figure 1. Section from a 1953 advertisement featuring the Honeywell Round (left). The ad included the text: "Different from any thermostat you've ever seen. The snap-off cover of the Honeywell Round makes it easy to paint the silver-bronze cover to match any decorating scheme. This means you can paint it to blend with any wall." The Nest thermostat (right), first released in 2011, has focused new attention on thermostat design and usability. Photo used with permission from Nest Labs.

\subsection{The Evolution of Thermostats}

To understand the interplay of thermostat design and family practices, it will help to briefly review the genesis and evolution of residential thermostats. Our goal is not to provide an exhaustive history (see [33] for an excellent historical overview); rather, we discuss interesting points in the development of a design language for thermostats that has persisted to the present day. Starting in the 1950s Honeywell International released the first of its round thermostats (Figure 1). Designed by Henry Dreyfuss, the round thermostat was simple and elegant and the same basic design is still in wide use over six decades later [33]. In some ways, however, much has changed. For example, Internet thermostats that allow users to program settings from anywhere in the world are becoming increasingly popular. Productssuch as Ecobee and Nest are dramatically rethinking the design of thermostat interfaces, and researchers are pushing these boundaries even further. For example, Yun and Gross [47] created the RayMatic, an anthropomorphic thermostat that represents temperature with an animated face displayed on a tablet computer.

Another important moment in the history of thermostats wasthe widespread adoption of programmable thermostats starting in the mid-1990s. Programmable thermostats are devices that automate temperature regulation in homes, ostensibly increasing efficiency and cutting heating and cooling costs. According to Energy Star, a joint program of the U.S. Environmental Protection Agency and the Department of Energy, "properly using a programmable thermostat at home is one of the easiest things you can do to lower your energy costs. It's as simple as set and save" [9]. Despite this optimistic assessment, there are several shortcomings in the user interfaces of these devices that fundamentally limit their effectiveness [22, 31, 37]. As a result,their programming capacities are widely underutilized [8, 31, 33]. In response to studies 
demonstrating a lack of energy savings, the U.S. Environmental Protection Agency announced that it would sunset the Energy Star specification for programmable thermostats as of 2009 [10].
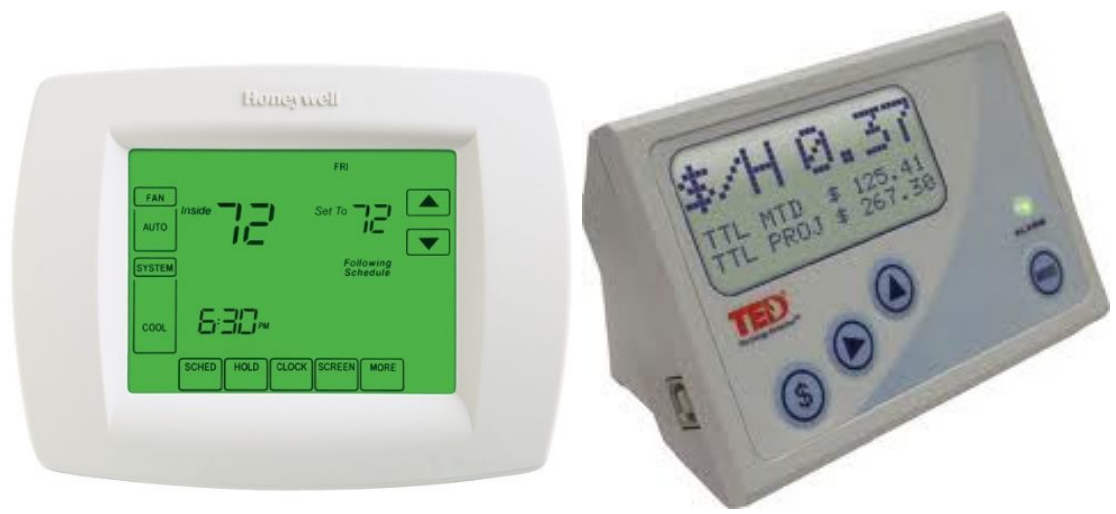

Figure 2. A typical programmable thermostat (left) with a backlit, touch-screen display. Families program temperature settings based on their day-to-day schedules.An in home display unit (right) for a smart meter showing electricity consumption information.

A notable evolution in thermostat design was the release of the Nest thermostat in October 2011. The Nest combines sophisticated interaction design, machine-learning algorithms to assist with programming, and wireless connectivity to the Internet. What is striking about the Nest, however, is the continuity of the design language from the Honeywell round of the 1950s (Figure 1). In a similar fashion, there are clear design parallels between many commercial smart meters and conventional programmable thermostats (Figure 2), raising the possibility that family practices around the use of heating and cooling systems could be replicated in other forms of eco-feedback technology.

\section{Study}

Over a two-year period we conducted a series of semi-structured interviews with 23 families in the greater-Chicago area about domestic water and energy consumption. All of the interviews took place in participants' homes and included at least one parent and one child between five and fifteen years old. These interviews were part of a larger project to design technology to engage children and families in informal learning around resource consumption and environmental sustainability. In our family interviews we began to notice that children had limited involvement in the management of heating and cooling systems through the use of thermostats. Because our ultimate design goal was to engage youth, we restructured sections of our interviews to try to understand practices around thermostat use in greater detail. In this paper we present results from ten of the family interviews that had this new focus on heating and cooling systems. All participating families had at least one thermostat in their home.

\subsection{Participants}


A total of 17 adults and 39 children participated in our study. Our family participants included 14 adults and 20 children from 5 to 15 years old. Six families reported having programmable thermostats, although two of the six families had not programmed any settings. Our families came from a diverse range of neighborhoods and economic backgrounds. To triangulate findings in our family interviews, we also conducted four focus group interviews with children to hear their perspectives in a parent-free setting. For the first round of focus groups, participants were recruited from a local seventh grade science classroom. The school primarily serves middle-income families with diverse backgrounds. Eight children (four girls and four boys, ages 13-14 years) volunteered with parental consent and were randomly assigned to two groups with one group of five and another of three. The interviews took place in a small science room during the students' regular study hall period. For the second round of focus groups, we recruited participants from an urban afterschool program serving children of immigrant families. Eleven children ( 2 girls and 9 boys, ages 5- 17 years) volunteered with parental consent. Given the spread of ages in this group, the participants were put into two groups: 5-8 years old (5 participants), and 9 years old and older (6 participants). The interviews took place in the main cafeteria as part of the children's daily session. Additionally, we conducted two semi-structured interviews with thermostat installation experts. One of the thermostat installers worked primarily in a suburb of a major midwestern city in the United States, while the other worked in a suburb of a major northeastern city. Both installers were male, and each reported having 25 years of experience installing thermostats. These interviews were similar to our family interviews, but we also asked questions about how thermostats were selected for homes, how settings were initially entered (for programmable thermostats), and what kinds of advice were offered to families in terms of energy management. Finally, we conducted one semi-structured interview with a thermostat designer, engineer, and member of the executive team from a small thermostat design company that focuses on Internet-connected thermostat designs. This interview focused on thermostat design considerations and tradeoffs.

\subsection{Research Questions}

As stated above, the larger goal of this project is to think about how to involve youth (along with other family members) in learning about household energy consumption and sustainability. With this goal in mind, our interview analysis wasguided by the following specific research questions: What role, if any, do children and adolescents play in helping families manage heating and cooling systems? What factors influence their participation? And, how does participation change as children get older?

\subsection{Methods}

Our analysis followed a grounded theory approach [4]. We worked from text-based transcriptions of interviews as well as from source video recordings to note participant gestures, facial expressions, and interactions with thermostats. Our initial passes through the data 
generated a list of questions about what participants were saying, what seemed to "go without saying", and when participants seemed to contradict one another (or themselves). Based on these questions we then conducted a microanalysis of four focal interviews to identify themes and subthemes that were consistent across interviews or that stood out as anomalous. We selected focal interviews that included especially rich family conversation,or that represented what seemed to be diverse viewpoints. Comparing and contrasting all of the interviews and focus groups with respect to these themes, we attempted to derive dimensions of attitudes, norms, and practices with a focus on factors that seemed to impact youth involvement. We then applied these dimensions to our entire corpus. In presenting our findings, we use interview excerpts to illustrate these themes and dimensions.

\subsection{A Note on Climate and Housing}

The Chicago area experiences wide seasonal variations with temperatures often dropping below $0^{\circ} \mathrm{F}\left(-18^{\circ} \mathrm{C}\right)$ in the winter and above $90^{\circ} \mathrm{F}\left(32^{\circ} \mathrm{C}\right)$ in the summer. Heating systems were present in all of the homes in our sample, and central air conditioning was common. Some homes had no air conditioning or used removable window units instead of central air conditioning. Although all of the families in our study had at least one thermostat, it is important to note that many Chicago-area residents live in apartment units with no direct control over their building's central heating system. In some cases, individual radiators can be adjusted using valves. As mentioned above, we see central heating and air conditioning as just one interesting form of energy consumption in homes. Our goal in this study is to draw broader implications for a range of household energy consumption.

\section{Findings}

In our family interviews we started discussions about heating and cooling systems by asking families to show us their thermostat and demonstrate its use. Later we asked which family members adjusted the temperature. One of the most obvious findings was that rules around thermostat use, while mutually understood, were often not explicitly discussed among family members. The following conversation comes from an interview with a mother and two children, a son (in high school) and a daughter (in middle school). This family lived on the second floor of a two-family home in a low-income area of a Chicago suburb. The home was heated with forced air, and the family had installed a programmable thermostat that automatically raised and lowered the temperature.

\section{Family 1: Excerpt 1 - We're not allowed}

R: [to kids] So let me ask, do you ever change the temperature on the thermostat, or do you just change?

Girl: No.

Boy: We don't but mom does.

Girl: Not really.

R: $\quad$ She... you don't ever touch the thermostat; why not?

Boy: 'cause we're not allowed to.

Mom: Well I don't know if I ever allowed it, but I don't know if I ever prevented you but no, I don't encourage them to touch the thermostat. 
R: $\quad$ How do you know that you're not supposed to touch the thermostat?

Boy: I don't know I just kind of like, just it sort of happened, plus I never really care.

Mom: [Laughs]

R: You never really care, okay. [to daughter]: You never try to change the thermostat? You never touch it?

Girl: [Shakes head, no]

R: $\quad$ And you never told them that they're not allowed to touch it?

Mom: No, I don't think so.

R: $\quad$ So.... how do you know?

Mom: [Laughing] I mean, you know, so they say, "hey I'm cold”, I say, put on a sweater.

This discussion illustrates several other recurring themes that emerged across a number of interviews. First, there appeared to be a mutual understanding on the part of many parents and children that thermostats are for adults only, although there was some variation that we discuss below. Children, like the son in this interview, often reported that they were not allowed to touch the thermostat even though many parents said that they had no memory of explicitly prohibiting use. As one girl from a focus group explained, "there are kind of rules, but they're not tightly set [...] if I come home one day and change the temperature and mom gets mad I know its not a good idea next time." Rather than explicitly prohibiting use, many parents seemed to prefer a strategy of offering options for achieving thermal comfort that did not include adjusting the thermostat. This almost always involved putting on or taking off clothing or blankets. Other alternatives that were mentioned included opening or closing windows, turning on fans, or even going to the store to buy a personal heater. Interestingly, attitudes around young people's use of localized heating and cooling devices such as space heaters, fans, and window air-conditioning units seemed more relaxed than that of centralized systems, even though the localized devices can contribute substantially to overall energy consumption. For example, several kids reported adjusting the temperature on window $\mathrm{A} / \mathrm{C}$ units or turning on space heaters.

In explaining how he knows he's not supposed to touch the thermostat, the boy in the prior interview segment said that "it sort of happened, plus I never really care." Several children in other families reported a similar lack of interest in the thermostats in their homes. In one family, the children did not know where their thermostat was located. This is perhaps not surprising asthermostats seem to be designed to blend in rather than to stand out. For example, one version of the Honeywell Round thermostat (Figure 1, left) was designed to be painted so that it would match a home's décor. Similarly, the Nest (Figure 1, right) was designed using a "chameleon" metallic outer ring that reflects the color of the wall.

\subsection{Issues of Trust}

Of the families we interviewed, there was one in which the expectations of the parent seemed to differ from that of the child, an adolescent boy. This family lived in a single-family home heated with forced air. Although they had installed a programmable thermostat, the family reported using it like a manual thermostat without programming the settings. In the interview, the father challenged his son's claim about thermostat use. Although the father's stance is more 
direct than the mother in the first excerpt, he reportedusing similar strategies to enforce behavior, namely suggesting other means to achieve thermal comfort:

\section{Family 2: Excerpt 1 - Fiddling around}

$\mathrm{R}$ : Okay, do you [to son] ever touch the thermostat or is that something you leave? Are you the one who usually touches...

Son: I like fiddling, I like fiddling around with it...

Dad: $\quad$ But you don't mess with the thermostat.

Son: $\quad$ Yes I do. Remember sometimes I change it, like I used to, um, change it from hot to all the way freezing.

Dad: $\quad$ No, you've never done that, Kurt.

Son: $\quad$ Yes I have.

Dad: Okay, well, I don't think that's accurate.

Son: Yes.

R: Why, so if you're the one who usually... why are you the one who usually does it? Why isn't he supposed to do that?

Dad: Because he just... we try to put blankets and dress warmer instead of raising the heat.

$\mathrm{R}$ Okay, and so you prefer that as a solution?

Dad: Yeah.

R: Okay.

Dad: Yeah, it's a lot more environmentally intelligent.

R: $\quad$ Okay.

Dad: And cheaper.

In this exchange, the son's insistence that he "likes fiddling around" with the thermostat seemed to violate an unspoken expectation on the part of the father, who openly disagreed with his son. In his explanation, the father emphasized concerns about energy use, environmental impact, and financial expenditure. Other parents in our interviews voiced similar concerns. By raising these issues, the father implied that his son could not be trusted to act in a way that would conserve energy and money. Later in the interview, the researcher discussed the possibility of remotely controlling a thermostat using an Internet-enabled device like an iPad. The father reinforced his concerns and expanded on his thinking about shared thermostat use:

\section{Family 2: Excerpt 2 - Paying the bill}

Dad: We'd probably have like one person that did it.

Son: Me! [Raises hand]

R: What about the thermostat makes sense having one person do it as opposed to having multiple people have access?

Dad: Because then you just sorta have, you just sorta have the thing of, you know, if you're cold put a coat on. If you're hot put a short sleeve shirt on. As opposed to just go crank up the heat, or crank up the air. It's just too easy to do that as opposed to dressing appropriately. You know when it's 25 [F] below and the winds are blowing, you know ... you're house is going to be cold. That's just it. You can crank the heat up and have it running the whole time or you can just put something warmer on.

Son: $\quad$ Oh, that's really nice.

Dad: And, you know, it just takes a while to bring that concept.

R: $\quad$ So that's something that you sort of learn over time.

Dad: When you're paying the bill, yeah. You learn when you're paying the bill. That's the difference between renting and owning. You know, I mean when you're renting, someone's just paying for the heat you just turn it up. 
Again, by saying that it's "just too easy" to "crank up the heat" the father implied that if you're not paying the bill you can't be trusted to act responsibly because you don't fully appreciate the implications of your actions. In this view children are seen as oblivious to the real costs of energy consumption. The tradeoffs between comfort and money are only understood in the adult world of earning an income and paying bills. The father's argument also highlights the bill as the primary energy feedback mechanism and money as the unit of measure (see [25] for an interesting discussion of folk units of energy). Because this mechanism of feedback tends to be exclusively for adults, the participation of youth is seen as problematic, not only in terms of alack of information but also in terms of understanding money as a resource to be conserved.

The father's view was representative of an entrenched resistance to the involvement of youth on the part of many parents that we talked with. In these cases there seemed to be no perceived safe or acceptable way for kids to get involved. As one focus group participant put it, "my parents would yell at me if I did [touch the thermostat]." These sentiments were echoed in our interviews with the thermostat designer and the thermostat installers.

\section{Installer 1: Excerpt 1 - If I could lock it up, I would}

R: $\quad$ Do you think kids should touch thermostats?

Bob: I don't think my wife should touch the thermostat!

R: $\quad$ Can I ask why not?

Bob: If I could put a box on it and lock it up like you see in an office building, I would.

In not directly answering the question, the installer's response indicates that there is a sense of distrust in the capabilities of others with regard to thermostat use, so much so that he would lock it up if he could. The distrust of both kids and spouses was also echoed in our second installer interview:

\section{Installer 2: Excerpt 1 - You can outfox your spouse}

Paul: You can outfox your spouse. My wife insists that she likes to sleep warm and not sleep in a cold environment, which I like to do. But she's been sleeping in a cold environment for all these years, she just doesn't know. [chuckles] I have the thermostat set to go off at 11:30 when she's asleep, and it turns on at 6 o'clock, before she's up, so she, uh, she has no idea that she's a cold sleeper.

What is interesting in this example is the sense in which Paul not only opposes his wife's involvement but also actively keeps her in the dark (and the cold), suggesting that he believes that he has a better understanding of her thermal comfort than she does.

\subsection{Involving Kids}

Not all families were opposed to having kids adjust thermostats, and in some cases involvement was not only condoned but encouraged. For example, one family reported being very conscious of their environmental impact. Among other strategies, they used a solar water heater in combination with a forced air system to heat their home using less fuel. They also gave tours of their home to showcase their energy saving techniques to the community. The family's two 
boys (ages 14 and 15) reported adjusting the temperature on the family's programmable thermostat on rare occasions, and the parents seemed to value this as an educational opportunity. However, in the interview, echoing the sentiment of the son from Family 1, one of the boys commented: "we normally don't [mess?] around because we don't feel like it." Likewise, many of the children in our suburban school focus group reported that they would sometimes adjust the thermostat or that their parents would ask them to turn it up or down a few degrees: "all you have to do is look at the degrees and see how you want it." However, despite reporting adjusting the thermostat, when asked what a normal indoor temperature might be, answers ranged from $40^{\circ}$ to $100^{\circ} \mathrm{F}$ (approximately $4^{\circ}$ to $40^{\circ} \mathrm{C}$ ) with most admittedly guessing. Similarly, none of the 14 interviewed teenagers knew what kind of heat was used in their homes with guesses including "thermal" and "electrical".

In some instances there was a sense that thermostat use could be a learning opportunity, even when viewed in a somewhat negative light. Paul, the installer, describeda mental "model" held by his son that is reminiscent of Kempton's description of thermostat folk theories [24].

\section{Installer 2: Excerpt 2 - Turning the heat up to Bahamas}

R: $\quad$ Does he use the thermostat? [In reference to the installer's son]

Paul: He hasn't shown any interest, actually. I don't like him to, no I don't.

R: $\quad$ Any reason why not?

Paul: Yeah, he turned it way the heck up. He did the gas accelerator model. I'm a little cold so I'm going to turn it up to $85[\mathrm{~F}]$.

R: $\quad$ Did that turn into a learning experience?

Paul: $\quad$ Yes it did [chuckles]

R: $\quad$ Did you teach him what could have been done differently?

Paul: $\quad$ Yes I did, I said, you know, again I don't think it really registered, but I did state that, you know 75 is plenty warm. 85 is Bahamas. [chuckles]. We don't need the Bahamas here, please don't turn it up as high again. And he hasn't, he's very good about if I lay out a boundary he's very good about not crossing it.

Here Paul explainedlearning as successfully communicating temperature boundaries to his son. But notable in this exchange was the idea that Paul's son could be involved in thermostat use with appropriate guidance and supervision. We saw similar evidence of limited learning activity from the kids in our interviews as well. One girl from a school focus group explained that she had seen her parents use the thermostat, prompting her to question what it was. "Two or three years ago I understood what it was for. I saw my parents using it [...] and then figured out 'oh it changes the temperature', and then someone would say 'oh it's cold would you turn the thermostat down'. I've seen them use it and I ask a ton of questions usually, so I asked and they explained it." Both of these examples suggest variation in family attitudes and interest on the part of children. This also suggests that thermostats couldserve as a focal point for learning about temperature, fiscal responsibility, household infrastructure, and potentially even environmental sustainability. This was somewhat surprising in the case of Paul, who had earlier reported hiding settings from his wife. 


\subsection{Youth Explanations for Lack of Involvement}

Even though some parents reported that they were open to the idea of allowing their children to adjust the thermostat if they wanted to, children offered a range of explanations for their lack of involvement, the most common being a lack of interest. The following interview included a mother, and three children, from a low-income area located on the south side of Chicago: Jaye (7), Amal (11), and Dorie (5). This family had a manual thermostat with a central heating system.

\section{Family 3 - Thermostats are just confusing}

R: A thermostat? Okay. And, do you have one of these in your house?

Dorie: Yes.

R: $\quad$ Do you, do the kids ever use it?

Jaye: No.

Mom: Shouldn't...

R: $\quad$ They shouldn't? How come?

Mom: Because ... it has to be parent regulated.

R: $\quad$ And...

Mom: Although, Amal can use it sometimes.

R: Do you use it ever? [to Amal]

Amal: No.

R: No.

Mom: Have you used it ever?

Amal: No.

Mom: You've never turned it on at all?

Amal: No.

R: $\quad$ Why don't you think you have ever turned it on or off?

Amal: We don't pay attention to it. If it gets too hot I just turn on a fan.

R: Okay.

Amal: Because some of that stuff is just confusing, and I don't know how it works.

R: $\quad$ What if it gets too cold?

Amal: Then I might complain about that though.

R: $\quad$ So, if you wanted to change the temperature you would complain?

Amal: Hm hmm. [agreement]

R: Okay. What about you? [to Jaye] What if it gets too hot or cold? What do you do?

Jaye: Hmm. If I am felling cold I will just put on some warm pants or long sleeves. If it was too cold I would just, hmm, find some other way to be warmer.

Here, the mother insisted that thermostat use should be parent regulated, but she also indicated that it would be acceptable for the older son, Amal, to adjust the temperature if he wanted to. Despite this, Amal claimed that he never touchedthe thermostat and instead offered three explanations for his lack of involvement. His first explanation is that he simply doesn't "pay attention to" the thermostat echoes our earlier finding as does his second explanation that he seeks other means of thermal comfort (such as turning on a fan, complaining to a parent, or putting on clothes). His argument implied that it's not necessary to adjust the thermostat when there are better options available. What is not clear is why children perceived these options to be better, especially when many adults such as the father in Family 2 argued that adjusting the 
thermostat was "too easy." Amal's third explanation sheds some light on this question by contradicting this ease-of-use argument when he says: "some of that stuff is just confusing, and I don't know how it works. "In part, Amal's reluctance stems not only from a lack of interest but also from but also from uncertainty about how the thermostat works.

\subsection{Fear and Uncertainty}

Beyond finding thermostats difficult to understand, several parents and children also said that they didn't touch their thermostat because they were afraid they would "mess it up" or even break it. For example, the mother in Family 1 at different points called the thermostat a "fussy kind of thing" and "a little bit tricky," suggesting thermostats carry the impression of fragility or even danger. Prior studies of thermostat use by Finnish residents reached similar conclusions $[22,23]$. An extreme example came from an interview with a mother and her six-year-old daughter. This family had a programmable thermostat with central heating and programmed settings:

\section{Family 4 - Risk of getting burned}

R: $\quad$ So she's never touched the thermostat. Did you tell her not to?

Mom: No.

Girl: I don't want to. At the risk of getting burned.

R: $\quad$ At the risk of getting burned? Why do you think you'd get burned?

Girl: 'Cause you might touch the thermostat and you might get an electrical shock?

R: Okay.

Girl: Like I did on the stove when I touched it when it was hot.

R: $\quad$ So you never told her to... She just knows?

Mom: No. She just never asked. She's a little risk averse. So if she thinks there's any chance there might some injury involved she doesn't want to do it.

R: $\quad$ Uh huh. If she ever asked you if she could...

Mom: I would say that'd be fine.

What is most striking in this interview is the daughter's fear of the thermostat - a fear not only of using the device incorrectly, but a fear of physical harm. In fact, she equated thermostat use to touching the stove and getting a burn or electric shock. While this was the most extreme form of this theme in our data, multiple participants expressed trepidation around the idea of programming or even touching thermostats. Also interesting is the mother's indication that it would be fine for her six-year-old to adjust the thermostat if she wanted to.

\section{Discussion}

Our analysis is based on interviews conducted in one region of the United States, but our finding that children and adolescents rarely (and often never) touch thermostats in homes was consistent across a range of families. Parents expressed concerns about financial expenditure, environmental impact, and energy use. This seemed to translate into a sense that children couldn't be trusted to act responsibly because they didn't fully understand the financial implications of thermostat adjustments. In turn, parents themselves have difficulty understanding how thermostats work $[22,23,31,33]$, how heating systems in general function 
[24], and the financial and energy implications of adjusting thermostat settings. In many cases parents in our interviews reported that they were worried about "messing up" or even breaking thermostats. Words and phrases like "fussy", "tricky", and "mess it up" paint a picture of thermostats as fragile and confusing devices that control dangerous and costly systems [22, 23]. Kids, on the other hand, reported a lack of awareness or interest in thermostats. Like parents, they often said that thermostats were confusing or even dangerous. And, like parents, they reported using other means to achieve thermal comfort. Regardless of whether parents explicitly opposed or condoned their involvement, most kids in our interviews seemed to have the perception that thermostats were to be avoided.

To help put this into perspective, consider a hypothetical continuum of youth participation. At one extreme we can imagine homes in which kids never touch thermostats. In these homes parents are solely responsible for making energy consumption decisions that affect the entire family. At the other extreme we can imagine homes in which young people are full participants in the management of heating and cooling systems. They are involved with adults in negotiating temperature settings, monitoring energy use, and programming settings. Given such a continuum, we could further imagine a process by which a child's involvement might change over time, moving from limited to more active participation as the child grows older. Through such a process, a young person could become a knowledgeable collaborator with parents, consistent with views of learning as a transformation of participation over time [30, 38, 39]. We saw some evidence of these kinds of transformations when, for example, parents would ask their kids to adjust the temperature up or down a few degrees. However, most kids seemed to exist close to the opposite end of the continuum. We see this in contrast to other forms of family activity in which there are pathways through which the role of children expands over time. For example, consider cooking, cleaning, and the use of power tools. All of these activities are potentially dangerous; yet, there are also culturally acceptable means of involving children even at young ages. For example, there are toys that facilitate playacting (e.g. toy kitchen sets or workbenches). As children get older, they can become involved in the actual practices under varying degrees of adult supervision. The pathways for youth involvement in heating and cooling systems seem less obvious, raisingnew challenges for design in the future: could there be forms of participation that are perceived to be safe and in whichthe input of childrenis both accepted and valued? And could there be ways to make the activities of adults more visible to youth?

\subsection{Design Implications}

We conclude withtwo design considerationsbased on our analysis. Our long-term goal is to create opportunities for informal, intergenerational learning in homes, taking advantage of both family practices and evolving interactive technologies and infrastructures. Even though our study was conducted in one region of the United States and involved only one form of energy consumption, we believe there are broader implications for interaction designers interested in involving families and children in more environmentallysustainable practices. This first 
consideration is that design language matters. The vocabulary established by design elements, forms, and conventions can communicate powerful messages about how things should be used and who is allowed to use them. In the case of heating and cooling systems, the tendency for thermostats to be adult-only devices - and incidentally used by men more often than women [23] - appears in some ways to be an artifact of a design language established at least sixty years ago that has persisted even in the most modern and cutting-edge thermostat designs (Figure 1). Prevalent thermostat design decisions (such as mounting devices on walls at adult height and keeping controls small an nondescript) seem to both reflect and reinforce cultural expectations on role of youth.Many other household energy consumption devices follow a similar design formula (such as the electricity meters shown in Figure 2). The child-computer interaction community is in a unique position to think about how to make household energy consumption information more accessible to children. But, as designers create new technologies and new interfaces, there is a strong tendency to carry forward established design languages. Doing so has the advantage of communicating purpose and functionality, mitigating anxiety around new technology, and grounding designs in the familiar and comfortable. The Nest thermostat is a perfect example. Even though it is radically different from electro-mechanical thermostats, it looks and feels like a traditional round thermostat of 60 years ago. Arguable, this helps new users feel less trepidation around installing a smart, digital thermostat. On the other hand, subtle aspects of design can propagate culturally embedded expectations around youth involvement [19]. The implication for designers is that energy management technology has the potential to communicate a hands-off attitude even if that is not the intention.

Second, one way to make thermostats less intimidating could be to make the implication of adjustments more transparent. For example, many devices can now log a variety of information including energy consumption, indoor and outdoor temperatures, and the state of the device (e.g. whether the fan is or furnace are on or off). With wireless digital technology and highresolution interactive displays, it could be possible to visualize this information in more comprehensible ways. It would be relatively straightforward to build a computer simulation that could predict future consumption based on weather forecasts, past consumption rates, and device settings. So, for example, a family could adjust the nighttime temperature down a couple of degrees in the winter and instantly see resulting savings over the course of a month. If such information were easy to interpret, it might alleviate the sense of risk that sometimes accompanies adjusting or reprogramming a thermostat.

Here, research on games and learning offers clear guidance to motivate participation (e.g. [14, $41,44]$ ) including offering steady but increasingly difficulty challenges, providing just-in-time scaffolding and feedback, and offering clear ways to track progress over time. We implemented such an interface as part of a family game that we created called "Turn Up the Heat" [20]. With this design, families first set a thermostat and then see predicted outcomes in terms of energy consumption, money, and comfort (Figure 3). Our playtesting sessions with this game suggest that families have the ability to interpret such simulations to make sense of their everyday 
circumstances. Particularly interesting is the role that older children and adolescents played in many families. They were important interpreters of the representations used the simulation for both their parents and younger siblings.
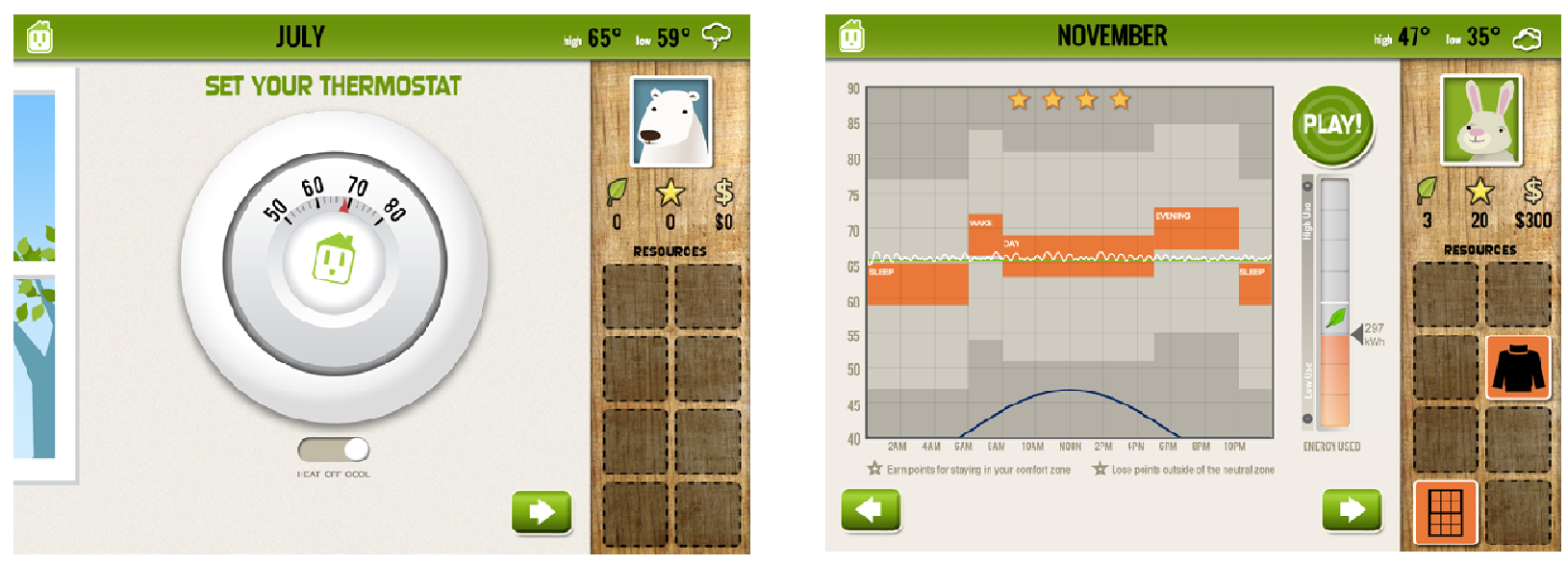

Figure 3. Two screens from the game, Turn Up the Heat. In the game families set a thermostat (left) as a way to earn comfort points and green points while conserving energy and money. The screen on the right simulates indoor temperatures based on the thermostat settings and the outside temperature.

In conclusion, this paper presents a qualitative analysis of how children and families use residential thermostats. Our intention is to use thermostats as one example to think about the broader case of household energy consumption technology and understand factors that might encourage or discourage the involvement of children. Technology is changing rapidly. How children participate in thinking about and managing household energy consumption is something that families will have work out for themselves. But, it would be naïve to assume that designers have no role in shaping attitudes and norms about the appropriateness of involving children and helping the next generation learn how to be more sustainable.

\section{Acknowledgements}

Pryce Davis, Aleata Hubbard, Mallessa James, Danielle Kiefert, Izabel Duarte Olson, and Laurel Schrementi contributed to this work. This research was supported by the Institute for Sustainability and Energy at Northwestern (ISEN) and the National Science Foundation (grant IIS-1123574). Any opinions, findings and conclusions or recommendations expressed in this material are those of the authors and do not necessarily reflect the views of the Foundation.

\section{References}

[1] Arroyo, E., Bonanni, L., \& Selker, T. (2005). Waterbot: Exploring Feedback and Persuasive Techniques at the Sink. In Proc. ACM Conference on Human Factors in Computing Systems (CHI'05), 631-637. New York: ACM Press. 
[2] Ballantyne, R., Connell, S., \& Fien, J. (2006). Students as catalysts of environmental change: a framework for researching intergenerational influence through environmental education. Environmental Education Research, 12(3-4), 413-427.

[3] Chetty, M., Tran, D., and Grinter, R.E. Getting to green: Understanding resource consumption in the home. In Proc. UbiComp'08, ACM Press (2008), 242-251.

[4] Corbin, J. \& Strauss, A. (2008). Basics of qualitative research: Techniques and procedures for developing grounded theory ( $3^{\text {rd }}$ edition). Sage.

[5] Darby, S. (2006b). Social learning and public policy: Lessons from an energy-conscious village. Energy Policy, 34, 2929-2940.

[6] Dillahunt, T., Mankoff, J., Paulos, E., and Fussell, S. (2009). It's not all about "green": Energy use in low-income communities. In Proc. UbiComp 2009, ACM Press, 255-264.

[7] DiSalvo, C., Sengers, P., and Brynjarsdóttir, H. Mapping the landscape of sustainable HCI. In Proc. ACM Conference on Human Factors in Computing Systems (CHI'10), ACM Press (2010), 1975-1984.

[8] Energy Information Administration. US Household Electricity Report. (2005). US Dept. of Energy, www.eia.doe.gov/emeu/reps/enduse/er01_us.html.

[9] Energy Star. (2010). Programmable Thermostat Video Podcasts. Energy Star. Accessed: June 16, 2015. http://www.energystar.gov/index.cfm?c=thermostats.PT_Podcast

[10] Environmental Protection Agency (2009). Letter to programmable thermostat manufacturer or other interested stakeholder. Accessed: January 14, 2011.

[11] Fitzpatrick, G. \& Smith, G. (2009). Technology-enabled feedback on domestic energy consumption: Articulating a set of design concerns. In Pervasive Computing, JanuaryMarch 2009, IEEE CS, 37-44.

[12] Froehlich, J., Larson, E., Campbell, T., Haggerty, C., Fogarty, J., \& Patel, S.N. (2009). HydroSense: Infrastructure-Mediated Single-Point Sensing of Whole-Home Water Activity. In Proc. Ubiquitous Computing (UbiComp'09). ACM Press.

[13] Froehlich, J., Findlater, L., \& Landay J. (2010). The design of eco-feedback technology. In Proc. ACM Conference on Human Factors in Computing Systems (CHI'10), ACM Press, 1999-2008.

[14] Gee, J.P. (2007). What video games have to teach us about learning and literacy. New York: Palgrave MacMillan.

[15] Goodwin, M.H. (2007). Occasioned knowledge exploration in family interaction. Discourse and Society, 18(1), 93-110.

[16] Gustafsson, A. \& Gyllensward, M. (2005). The power-aware cord: Energy awareness through ambient information display. In Proc. ACM Conference on Human Factors in Computing Systems (CHI'05), ACM Press, 1423-1426.

[17] He, H.A., Greenberg, S., \& Huang, E.M. (2010). One size does not fit all: applying the transtheoretical model to energy feedback technology design. In Proc. ACM Conference on Human Factors in Computing Systems (CHI'10), ACM Press, 297-936. 
[18] Hirsch, T. \& Anderson, K. (2010). Cross currents: Water scarcity and sustainable CHI. In Proc. ACM Conference on Human Factors in Computing Systems (CHI'10), ACM Press, 2843-2852.

[19] Horn, M.S. (2013). The role of cultural forms in tangible interaction design. In Proceedings Tangible, Embedded, and Embodied Interaction (TEI'13).

[20] Horn, M.S., Banerjee, A., D'Angelo, S., Kuo, P-Y., Pollock, D.H., Stevens, R. (2014). Turn Up the Heat! Board games, environmental sustainability, and cultural forms. In Proceedings Games, Learning, and Society (GLS'14).

[21] Horn, M.S., Davis, P., Hubbard, A., Keifert, D., Leong, Z.A., Olson, I.C. (2011). Learning Sustainability: Children, learning, and the next generation eco-feedback technology.In Proceedings of Interaction Design and Children (IDC'11), 161-164.

[22] Karjalainen, S. \& Koistinen, O. (2006). User problems with individual temperature control in offices. Building and Environment, 42, 2880-2887.

[23] Karjalainen, S. (2007). Gender differences in thermal comfort and use of thermostats in everyday thermal environments. Building and Environment, 42, 1594-1603.

[24] Kempton, W. (1986). Two theories of home heat control. Cognitive Science, 10, 75-90.

[25] Kempton, W. \& Montgomery, L. (1982). Folk quantification of energy. Energy, 7(10), 817-827.

[26] Kuijer, L., De Jong, A., Van EijK, D. (2013). Practices as a unit of design: An exploration of theoretical guidelines in a study on bathing. ACM Transactions on Computer-Human Interaction, 20(4).

[27] Kuznetsov, S. \& Paulos, E. (2010). UpStream: Motivating water conservation with lowcost water flow sensing and persuasive displays. In Proc. ACM Conference on Human Factors in Computing Systems (CHI'10), (pp. 1851-1860), New York: ACM Press.

[28] Latour, B. (1988). Mixing Humans and Nonhumans Together: The Sociology of a DoorCloser. Social Problems, 35(3), 298-310.

[29] Latour, B. (2000). Where are the missing masses? The sociology of a few mundane artefacts. In Bijker, W. E. \& Law J. (Eds), Shaping Technology/Building Society: Studies in Sociotechnical Change. MIT Press.

[30] Lave, J. \& Wenger, E. (1991). Situated learning: Legitimate peripheral participation. Cambridge University Press.

[31] Meier, A., Aragon, C., Peffer, T., Perry, D., \& Pritoni, M. (2011). Usability of residential thermostats: Preliminary investigations. Building and Environment, 46, 1891-1898.

[32] Patel, S.N., Gupta, S., \& Reynolds, M.S. (2010). The design and evaluation of an enduser-deployable, whole house, contactless power consumption sensor. In Proc. ACM Conference on Human Factors in Computing Systems (CHI'10), ACM Press, 2471-2480.

[33] Peffer, T., Pritoni, M., Meier, A., Aragon, C., \& Perry, D. (2011). How people use thermostats in homes: A review. Building and Environment, 46, 2529-2541. 
[34] Pierce, J., Schiano, D.J., Paulos, E. (2010). Home, habits, and energy: Examining domestic interactions and energy consumption. In Proc. ACM Conference on Human Factors in Computing Systems (CHI'10), ACM Press, 1985-1994.

[35] Pierce, J., Strengers, Y., Sengers, P., \& Bødker, S. (2013). Introduction to the special issue on practice-oriented approaches to sustainable HCI. ACM Transactions on ComputerHuman Interaction, 20(4).

[36] Riche, Y., Dodge, J., \& Metoyer, R.A. (2010). Studying always-on electricity feedback in the home. In Proc. ACM Conference on Human Factors in Computing Systems (CHI'2010), ACM Press, 1995-1998.

[37] Rode, J.A., Toye, E.F., \& Blackwell, A.F. (2004). The fuzzy felt ethnographyunderstanding the programming patterns of domestic appliances. Journal of Personal and Ubiquitous Computing, 8, 161-176.

[38] Rogoff, B. (2003). The Cultural Nature of Human Development. Oxford.

[39] Rogoff, B., Paradise, R., Arauz, R.M, Correa-Chávez, M., Angelillo, C. (2003). Firsthand learning through intent participation. Annual Review of Psychology, 2003(54), 175-203.

[40] Shove, E. (2003). Comfort, Cleanliness, and Convenience: The Social Organization of Normality. Berg.

[41] Squire, K. (2011). Video Games and Learning: Teaching and Participatory Culture in the Digital Age. Teachers College Press.

[42] Strengers, Y. (2011a). Designing eco-feedback systems for everyday life. In Proc. ACM Conference on Human Factors in Computing Systems (CHI'11), ACM Press, 2135-2144.

[43] Strengers, Y. (2011b). Negotiating everyday life: The role of energy and water consumption feedback. Journal of Consumer Culture, 11(3), 319-338.

[44] Stevens, R., Satwicz, T., \& McCarthy L. (2007). In-Game, In-Room, In-World: Reconnecting video game play to the rest of kids' lives. In K. Salen, (Ed.), The Ecology of Games: Connecting Youth, Games, and Learning, MIT, 41-66.

[45] Wakkary, R., Desjardins, A., Hauser, S. \& Maestri, L. (2013). A sustainable design fiction: Green practices. ACM Transactions on Computer-Human Interaction, 20(4).

[46] Woodruff, A., Hasbrouch, J., \& Augustin, S. (2008). A bright green perspective on sustainable choices. In Proc. ACM Conference on Human Factors in Computing Systems (CHI'08), ACM Press, 313-322.

[47] Yun, R. \& Gross, M.D. (2011). RayMatic: ambient meter display with facial expression and gesture. In Proc. ACM Conference on Human Factors in Computing Systems (extended abstracts), ACM Press, 341-346. 